\title{
Performance with robotic surgery versus 3D- and 2D-laparoscopy during pancreatic and biliary anastomoses in a biotissue model: pooled analysis of two randomized trials
}

\author{
Maurice J. W. Zwart ${ }^{1}$. Leia R. Jones ${ }^{1,2}$ (I) Ignacio Fuente $^{3} \cdot$ Alberto Balduzzi $^{1,4} \cdot$ Kosei Takagi $^{5,6} \cdot$ Stephanie Novak $^{7}$. \\ Luna A. Stibbe ${ }^{1}$. Thijs de Rooij ${ }^{1}$. Jony van Hilst ${ }^{1}$ - L. Bengt van Rijssen ${ }^{1}$. Susan van Dieren ${ }^{1}$. Aude Vanlander ${ }^{8}$. \\ Peter B. van den Boezem ${ }^{9}$. Freek Daams ${ }^{10}$. J. Sven D. Mieog ${ }^{11}$. Bert A. Bonsing ${ }^{11}$. Camiel Rosman ${ }^{9}$. \\ Sebastiaan Festen ${ }^{12}$. Misha D. Luyer ${ }^{13}$. Daan J. Lips ${ }^{14}$. Arthur J. Moser ${ }^{15}$. Olivier R. Busch ${ }^{1} \cdot$ Mohammad Abu Hilal $^{2}$. \\ Melissa E. Hogg ${ }^{16} \cdot$ Martijn W. J. Stommel $^{9} \cdot$ Marc G. Besselink $^{1} \cdot$ for the Dutch Pancreatic Cancer Group
}

Received: 27 April 2021 / Accepted: 17 October 2021 / Published online: 19 November 2021

(c) The Author(s) 2021

\begin{abstract}
Background Robotic surgery may improve surgical performance during minimally invasive pancreatoduodenectomy as compared to 3D- and 2D-laparoscopy but comparative studies are lacking. This study assessed the impact of robotic surgery versus 3D- and 2D-laparoscopy on surgical performance and operative time using a standardized biotissue model for pancreatico- and hepatico-jejunostomy using pooled data from two randomized controlled crossover trials (RCTs).

Methods Pooled analysis of data from two RCTs with 60 participants (36 surgeons, 24 residents) from 11 countries (December 2017-July 2019) was conducted. Each included participant completed two pancreatico- and two hepatico-jejunostomies in biotissue using 3D-robotic surgery, 3D-laparoscopy, or 2D-laparoscopy. Primary outcomes were the objective structured assessment of technical skills (OSATS: 12-60) rating, scored by observers blinded for 3D/2D and the operative time required to complete both anastomoses. Sensitivity analysis excluded participants with excess experience compared to others.

Results A total of 220 anastomoses were completed (robotic 80, 3D-laparoscopy 70, 2D-laparoscopy 70). Participants in the robotic group had less surgical experience [median $1(0-2)$ versus 6 years $(4-12), p<0.001$ ], as compared to the laparoscopic group. Robotic surgery resulted in higher OSATS ratings $(50,43,39$ points, $p=.021$ and $p<.001)$ and shorter operative time $(56.5,65.0,81.5 \mathrm{~min}, p=.055$ and $p<.001)$, as compared to 3D- and 2D-laparoscopy, respectively, which remained in the sensitivity analysis.

Conclusion In a pooled analysis of two RCTs in a biotissue model, robotic surgery resulted in better surgical performance scores and shorter operative time for biotissue pancreatic and biliary anastomoses, as compared to 3D- and 2D-laparoscopy.
\end{abstract}

Keywords Robotic $\cdot$ Laparoscopy $\cdot$ 3D-laparoscopy $\cdot$ Pancreas $\cdot$ Liver $\cdot$ OSATS

Minimally invasive pancreatoduodenectomy (MIPD) is becoming increasingly popular [1]. Recently, the singlecenter Spanish PADULAP and Indian PLOT randomized controlled trials resulted in shorter hospital stay and less complications with laparoscopic as compared to open

Maurice J. W. Zwart and Leia R. Jones Shared first authorship.

Leia R. Jones

1.r.jones@amsterdamUMC.nl

Marc G. Besselink

m.g.besselink@amsterdamUMC.nl

Extended author information available on the last page of the article pancreatoduodenectomy $[2,3]$. However, the first multicenter randomized controlled LEOPARD-2 trial was terminated early for safety concerns with laparoscopic MIPD which could have been related to a learning curve effect [4].

Robotic surgery aims to overcome the compromises made with 2D-laparoscopic surgery by improving dexterity, 3D vision, and ergonomic comfort [5-7]. Outcomes for robotic MIPD in retrospective series from expert centers seem promising, including a lower conversion rate as compared to laparoscopic MIPD [5, 8]. However, robotic surgery also has several downsides such as high costs, docking time, and loss of haptic feedback [9-12]. These shortcomings might be overcome by 3D-laparoscopy. Several authors have reported 
excellent outcomes with this approach [13, 14]. However, studies comparing surgical performance with robotic surgery, 3D-, and 2D-laparoscopy are currently lacking [15].

In recent years, use of artificial organs (biotissue) to improve surgical training in MIPD has gained popularity [16-20]. Since the declaration of Helsinki [21], several medical principles to safeguard the health, well-being, and rights of patients have been established, including simulation as a first step.

The aim of the present study is to assess surgical performance with robotic surgery, 3D-, and 2D-laparoscopy for the pancreatico- and hepatico-jejunostomy anastomoses of MIPD by pooling data from two previous randomized controlled crossover trials using the same standardized biotissue model.

\section{Materials and methods}

This study was reported in accordance with the Consolidated Standards of Reporting Trials (CONSORT) [22]. Data from two previous randomized controlled crossover trials, comparing robotic surgery and 3D- and 2D-laparoscopy in a biotissue model for pancreatico- and hepatico-jejunostomy (PJ and $\mathrm{HJ}$ ), were combined [19, 23]. The trials were registered in the Netherlands Trial Registry under code NL8063. The LAELAPS-3D2D trial compared 3D- and 2D-laparoscopy for the MIPD anastomoses [13] and the LAEBOT-3D2D trial compared robotic surgery with 3Dand 2D-vision [24]. In these trials, the participants had to complete a PJ and a HJ twice: once with 3D- and once with 2D-vision. The participants were randomized to start either with 3D- or 2D-vision in each anastomosis and had to crossover to the other anastomosis (HJ/PJ) in other vision modality, after completing the first anastomosis. The analysis was based on individual participant data, but since the designs of the studies were highly similar, data were fully pooled. Both studies were approved by the local ethics committee and performed in accordance with the Declaration of Helsinki [21].

\section{Participants}

Participating surgeons and residents were invited from all 17 centers collaborating within the Dutch Pancreatic Cancer Group along with related international centers. Based on sample size calculations, the LAELAPS3D2D trial included 20 surgical experts and 20 surgical residents. None of the participating residents had performed minimally invasive pancreas procedures independently. The LAEBOT3D2D trial included 20 participants without stratification on participant categorization as experts or residents, since no statistical difference was found in the LAELAPS3D2D trial $[13,24]$. All participants were capable of suturing with the minimally invasive approach, i.e., robotic or laparoscopic. Participants were excluded if they had no 3D-vision abilities, as evidenced by $<200$ seconds of arc on Randot Test (Stereo optical, Chicago, IL, USA) [25].

\section{Randomization}

In both trials, randomization was done with SPSS (SPSS, Chicago, IL, USA) by the study coordinator. Participant data were anonymized using a 4-digit code and only the principal investigator and study coordinators had access to the decoding document.

\section{Intervention}

The interventions in both trials were the same. In both trials, an identical standardized patient setting was simulated, using inanimate artificial, biotissue, organs (LifeLike BioTissue, Ontario, Canada) as previously published by King et al. [7] The specifics on the simulation set-up and biotissue were previously published in the LAELAPS-3D2D [13] and LAEBOT-3D2D [24] trials.

For robotic surgery, the integrated 3D HD da Vinci robotic laparoscope and robotic system was used (Intuitive, Sunnyvale California, USA). For laparoscopy, the ENDOEYE FLEX 3D (Olympus, Tokyo, Japan) 10-mm articulating laparoscope with high-definition vision was used. Participants first watched an instruction video and had an oral instruction before the start of the experiment. Hereafter, participants were allocated to complete a PJ and a $\mathrm{HJ}$ twice in the biotissue model, once with 3D- and once with 2D-vision. The anastomosis techniques and type and number of sutures were standardized, as means to compare the groups in this pooled analysis. Resolution (high-definition/1280 × 1024) and lighting conditions were identical between both interventions and approaches.

\section{Blinding}

Imaging material was rated by one rater who was blinded for both the performing participant and for 3D- or 2D-laparoscopy. The rater could not be blinded for robotic/laparoscopic surgery given the different instruments used. This rater was trained by $\mathrm{SN}$ and $\mathrm{MH}$ during a hands-on training in the University of Pittsburgh Medical Center. Performance was rated using an objective structured assessment of technical skills (OSATS) as validated by Birkmeyer et al. and Tam et al. [17, 26, 27]. Table 1 provides more details on the elements of the OSATS. 


\section{Outcomes}

Operative time was measured using video material and defined as the time between start of the first stitch to cutting the last stitch of one PJ and one HJ. Per participant, the total time to complete both PJs and HJs (i.e., time to complete four anastomoses) was taken into account. The primary outcomes were the difference in surgical performance expressed in OSATS (attainable range 12-60) and total operative time expressed in minutes and relatively in percentages. Secondary outcomes included stated side-effects and preferences as collected using questionnaires in both trials [13].

\section{Statistical methods}

Data were analyzed using IBM SPSS statistics for Windows version 26 (IBM Corp, Armonk, NY, USA). Normally distributed continuous data are presented as means and standard deviations (SDs). Non-normally distributed continuous data are presented as medians and interquartile ranges [IQRs] or $95 \%$ confidence intervals $(95 \% \mathrm{CI})$. Categorical (binary, nominal, and ordinal) data are presented as frequencies and percentages. Likert-Scale ordinal data are also presented in means and standard deviations, as this allows more insight into the effect size [28]. A two-tailed $p$ value $<0.05$ was considered statistically significant. Missing data were corrected by excluding the corresponding missing part of the video of both the intervention and control procedure into the analysis.

Baseline demographics were compared with Student's t-test for normally distributed data, Chi-squared test for frequencies in one or more categories, and Mann-Whitney $\mathrm{U}$ test for non-normally distributed data. The primary outcomes were analyzed according to Mann-Whitney U test because the samples were independent. To assess the impact of surgical experience, a sensitivity analysis excluded participants with $>7$ years experience (upper limit of experience in the group with the lowest experience) and experience in MIPD. Lastly, a sensitivity analysis was performed excluding those who participated in both trials.

\section{Results}

\section{Participants}

A total of 34 surgeons and 26 residents participated and subsequently performed anastomoses between December 2017 and June 2019. Three participants only completed one anastomosis, one participant left to perform an emergency procedure, and one participant performed the anastomoses in a running fashion. These five participants were excluded for the analysis of the primary and secondary outcome. Eight participants participated in both the robotic and laparoscopic trials. Figure 1 provides an overview of the inclusion and exclusion of participants in a flow chart.

\section{Baseline demographics}

The 55 included participants originated from 11 countries (Argentina, Belgium, Estonia, Israel, Italy, Japan, the Netherlands, South Africa, Spain, UK, and USA). Their mean age was 38 years (SD 9), 45 were male (80.0\%). The groups for robotic surgery and laparoscopy were comparable for age, sex, hand dominance, the number of MIPD performed in clinical practice, and stereopsis abilities. Participants in the robotic surgery group had less experience with robotic surgery (median 1 [0-2] versus 6 years [4-12], $p<0.001$ ), including a lower number of annual advanced minimally invasive procedures (median 20 versus $40, p=0.014$ ), compared to the experience of the laparoscopic group with laparoscopic surgery. In total, 15 participants from the

Table 1 Elements of objective structured assessment of technical skills (OSATS)

\begin{tabular}{ll}
\hline Grading definition & \\
1 & Deficient/traumatic \\
2 & Lacking/lacks finesse \\
3 & Average \\
4 & Skilled \\
5 & Master/flawless \\
Grading aspects and elucidation & \\
Gentleness & Gentle tissue handling that does not result in injury \\
Time and motion & Fluid use of instruments without awkwardness \\
Instrument handling & Economy of motion, maximum efficiency \\
Flow of operation & Smooth transitions from one part of the operation to another \\
Tissue exposure & Retraction that allows for good visualization and proper tissue alignment \\
Summary score & Overall assessment of technical skill \\
\hline
\end{tabular}


Fig. 1 Flowchart of Inclusion for Primary Outcomes

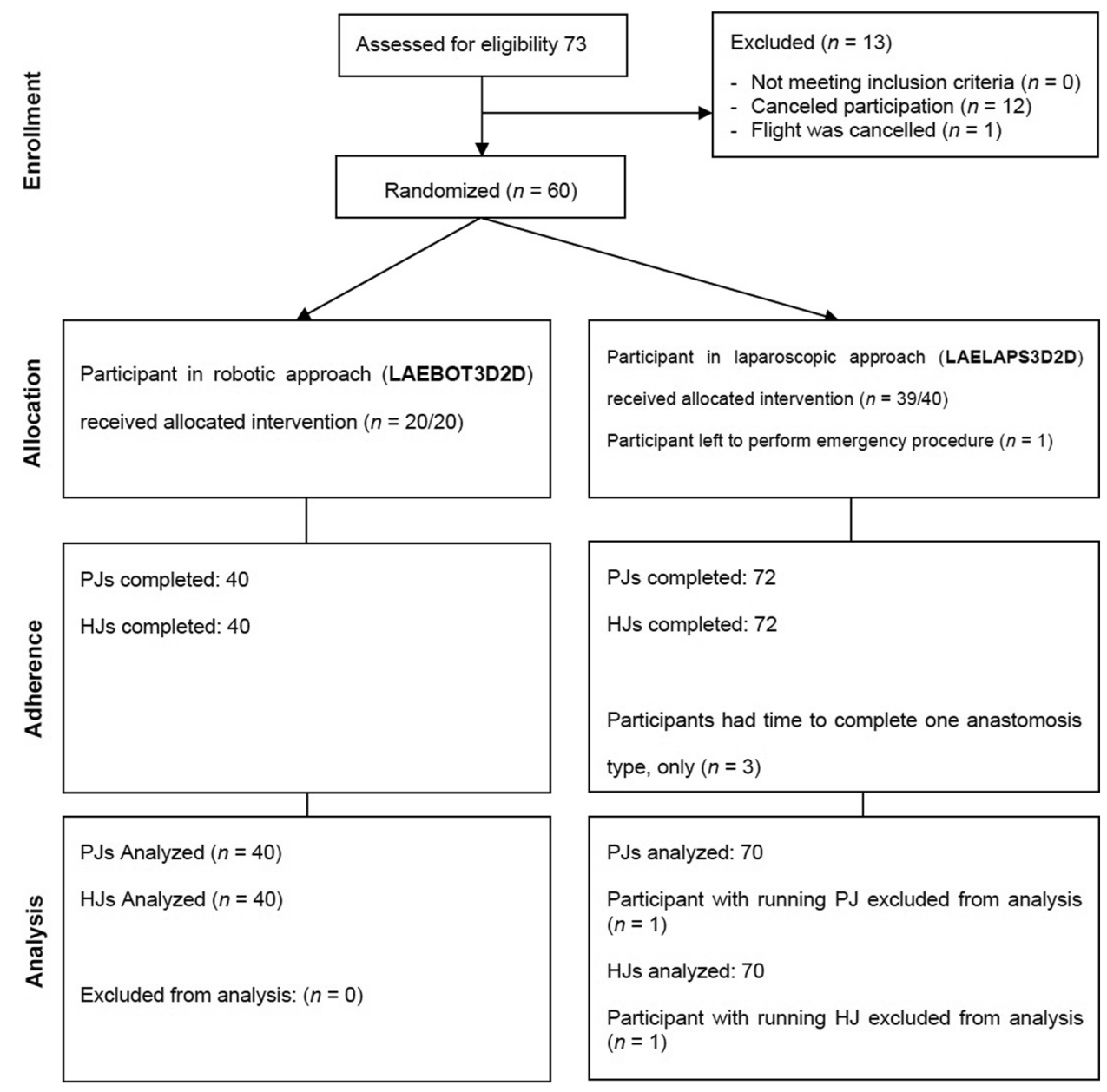

laparoscopic group had more than 7 years experience vs none in the robotic group. Table 2 provides an overview of baseline demographics of the participants and their subgroups of robotic surgery and laparoscopic surgery.

\section{Primary outcomes}

In the robotic surgery group, higher OSATS ratings were obtained (attainable range 12-60) as compared to 3D- and 2D-laparoscopy, median 50 [44-55] vs 43 [38-50] vs 39 [32-46]. Robotic surgery resulted in higher OSATS ratings by 7 points $(18.4 \%, p=0.021)$ and 11 points $(28.2 \%, p<$ 0.001 ), as compared to 3D- and 2D-laparoscopy, respectively. Figure 2 provides an overview of the OSATS scores for robotic surgery, and 3D- and 2D-laparoscopy.

In the robotic surgery group, operative time was shorter as compared to 3D- and 2D-laparoscopy: 56.5 min [52.4-67.5] vs $65.0 \mathrm{~min}$ [57.0-83.0] vs $81.5 \mathrm{~min}$ [68-97.8], $p<0.001$. In the robotic surgery group, operative time was shorter by $13.1 \%(p=0.055)$ and $30.7 \%(p<0.001)$, as compared to $3 \mathrm{D}$ - and 2D-laparoscopy. Figure 3 provides an overview of the operative times for robotic surgery as compared to laparoscopy, highlighting the superiority in robotic surgery.

\section{Secondary outcomes}

Of the 59/60 participants (20 robotic, 39/40 laparoscopic) who completed the survey on side-effects and preferences, $57 / 59(96.6 \%)$ preferred 3D-vision over 2D-vision (20/20 robotic, 37/39 laparoscopic). In the 3D-robotic group, 4/20 (20\%) participants reported one or more side-effects, i.e., eye strain (minor $n=2$ ), headache (minor $n=1$, serious $n=1$ ), dizziness (minor $n=2$, serious $n=1$ ). In the 3D-laparoscopy group, 14/39 (36\%) participants reported one or more side-effects. No significant differences were found between the two groups. Table 3 provides an overview on the complaints caused by $3 \mathrm{D}$ vision, highlighting the severity and the robotic and laparoscopic subgroups.

For the PJ, robotic surgery resulted in better OSATS ratings compared to 3D- and 2D-laparoscopy: 24 points [20-27] vs 22 points [18-25] vs 19 points [15-24]. Relatively, in the robotic surgery group, OSATS ratings were higher by $11.1 \%(p=0.004)$ and $27.8 \%(p=0.174)$, as 
Table 2 Participant characteristics

\begin{tabular}{|c|c|c|c|c|}
\hline & Total $(n=55)$ & $\begin{array}{l}\text { Robotic sur- } \\
\text { gery }(n=20)\end{array}$ & $\begin{array}{l}\text { Laparoscopic } \\
\text { surgery }(n=35)\end{array}$ & $p$ value \\
\hline Age, mean, SD & $38 \pm 9$ & $36 \pm 7$ & $39 \pm 9$ & $0.146^{\mathrm{c}}$ \\
\hline Male, n (\%) & $45(81.8)$ & $16(80.0)$ & $29(82.9)$ & $0.606^{\mathrm{b}}$ \\
\hline \multicolumn{5}{|l|}{ Surgical experience } \\
\hline $\begin{array}{l}\text { Years of experience with approach, } \\
\text { median [IQR] }\end{array}$ & $4[1-7]$ & $1[0-2]$ & $6[4-12]$ & $<0.001^{\mathrm{c}}$ \\
\hline $\operatorname{Expert}^{\mathrm{e}}(n=30)$ & & $1[1-2]$ & $13[9-16]$ & $<0.001^{\mathrm{c}}$ \\
\hline $\operatorname{Resident}^{\mathrm{r}}(n=25)$ & & $0[0-1]$ & $4[3-5]$ & 0.005 \\
\hline $\begin{array}{l}\text { Annual volume of advanced MI } \\
\text { procedures*, median [IQR] }\end{array}$ & $20[0-50]$ & $20[1-40]$ & $40[10-90]$ & $0.014^{\mathrm{c}}$ \\
\hline MIPDs performed, median [IQR] & $0[0-10]$ & $0[0-20]$ & $0[0-3]$ & $0.144^{c}$ \\
\hline Hand dominance, $\mathrm{n}(\%)$ & & & & $0.777^{\mathrm{b}}$ \\
\hline Right & $44(80.0)$ & $17(85.0)$ & $27(77.1)$ & \\
\hline Left & $7(12.7)$ & $2(10.0)$ & $5(14.3)$ & \\
\hline Ambidextrous & $4(7.3)$ & $1(5.0)$ & $3(8.6)$ & \\
\hline Vision correction, n (\%) & $24(43.6)$ & $9(45.0)$ & $15(42.9)$ & $0.877^{\mathrm{b}}$ \\
\hline Minimal degrees of stereopsis & $60[20-100]$ & $60[20-100]$ & $60[40-100]$ & $0.924^{\mathrm{C}}$ \\
\hline
\end{tabular}

Values are mean $\pm \mathrm{SD}$, median [quartile 1-quartile 3] or $n$ (percentage)

${ }^{\text {a }}$ Student's ttest, ${ }^{\mathrm{b}}$ Chisquare test, ${ }^{\mathrm{c}}$ Mann-Whitney U Test, *Minimally invasive surgery beyond appendectomy and cholecystectomy, experience as primary surgeon, ${ }^{\mathrm{r}}$ experience assisting or under direct supervision of primary surgeon

compared to 3D- and 2D-laparoscopy. Robotic surgery resulted in shorter operative time compared to 3D- and 2D-laparoscopy: $37.5 \mathrm{~min}$ [30.5-43.8] vs $39.5 \mathrm{~min}$ [35.5-50.8] vs 50.0 $\mathrm{min}$ [38.0-59.0]. Relatively, in the robotic surgery group, operative time was shorter by $5.1 \%$ $(p=0.176)$ and $22.0 \%(p=0.001)$, as compared to 3D- and 2D-laparoscopy.

For the HJ, robotic surgery resulted in better OSATS ratings compared to 3D- and 2D-laparoscopy: 27 points [26-29] vs 21 points [18-27] vs 18 points [16-24]. Relatively, in the robotic surgery group, OSATS ratings were higher by $28.6 \%(p<0.001)$ and $42.9 \%$ ( $p=0.002)$, as compared to 3D- and 2D-laparoscopy. Robotic surgery resulted in shorter operative time compared to 3D- and 2D-laparoscopy: $19.5 \mathrm{~min}$ [16.4-27.2] vs $25.0 \mathrm{~min}$ [19.0-34.0] vs $32.0 \mathrm{~min}$ [23.0-44.0]. Relatively, in the robotic surgery group, operative time was shorter by $22.0 \%(p=0.061)$ and $39.1 \%(p<0.001)$, as compared to 3D- and 2D-laparoscopy.

\section{Sensitivity analysis}

The sensitivity analysis excluded 15 participants with experience $>7$ years (upper limit of experience in the group with the lowest experience, the robotic group), all in the laparoscopy group. Table 4 provides the details on the participants' characteristics of the sensitivity analysis, highlighting the differences between subgroups. Baseline characteristics were comparable, yet years of experience with the approach remained significantly higher in the laparoscopic group $(p<$
0.001). However, number of MIPDs performed was significantly higher $(p=0.023)$ in the robotic group, even though the median number was 0 in both groups.

In the sensitivity analysis, the robotic approach still had a superior OSATS as compared to 3D- and 2D-laparoscopy, median 50 [44-55] vs median 35 [27-45] vs median 31 [26-36]. Robotic surgery resulted in higher OSATS ratings by 15 points $(52.1 \%, p=0.009)$ and 19 points $(60.4 \%, p=$ $0.006)$. The robotic approach still significantly resulted in shorter operative times: $56.5 \mathrm{~min}$ [52.4-67.5] vs $69.0 \mathrm{~min}$ [57.8-82.3] vs $81.0 \mathrm{~min}$ [65.0-95.5]. In the robotic surgery group, operative time was shorter by $12.4 \%(p=0.003)$ and $30.2 \%(p<0.001)$.

In an additional sensitivity analysis, we also excluded participants with experience in MIPD. After excluding participants with more than 7 years experience and experience in MIPD, the primary outcomes remained significantly better in the robotic group vs the 3D-laparoscopy group (OSATS ratings $p=0.005$ and operative time $p=0.008$ ). Finally, we excluded participants who performed in both the LAELAPS3D2D and LAEBOT-3D2D trial $(n=8)$. The results for the primary and secondary outcome remained consistent.

\section{Discussion}

This pooled analysis of two randomized controlled crossover trials found that robotic 3D-surgery resulted in better OSATS ratings and shorter operative time as compared 


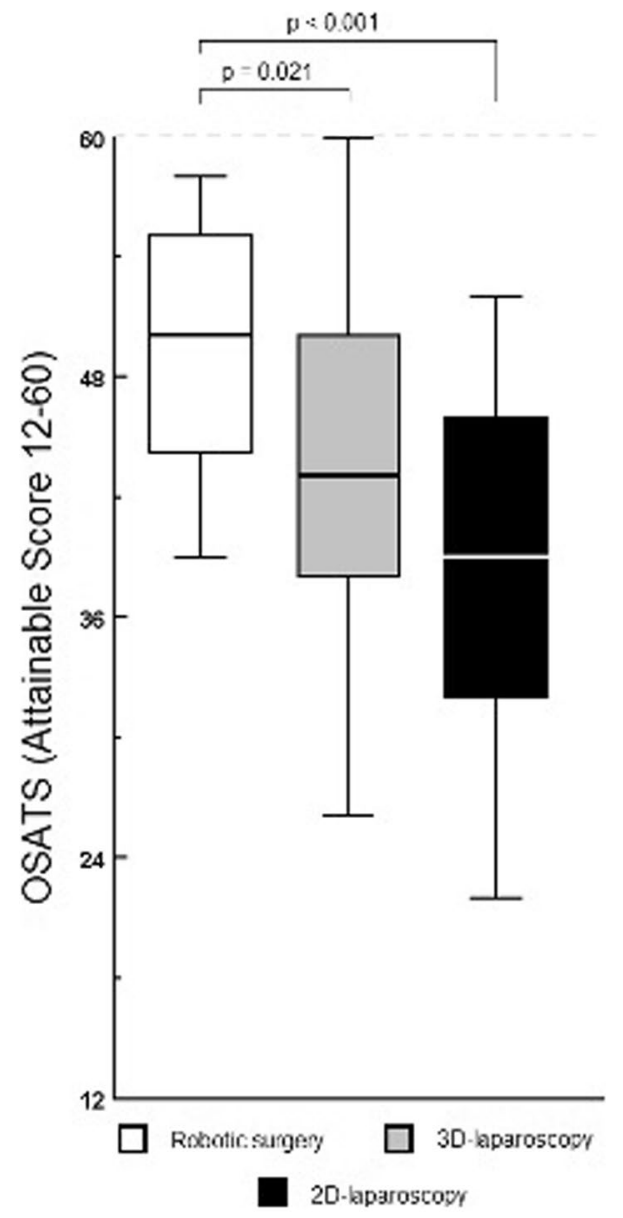

Fig. 2 Objective Structured Assessment of Technical Skills (OSATS) for robotic surgery, 3D-, and 2D-laparoscopy to complete biotissue pancreatico- and hepatico-jejunostomy anastomoses. Legend: From left to right: first, 3D-robotic surgery $(n=20)$; second, 3D-laparoscopy $(n=35)$; third, 2D-laparoscopy $(n=35)$

to both 3D- and 2D-laparoscopy in completing PJ and HJ anastomoses in a biotissue model. Although 3D-laparoscopy improved surgical performance for both operative time and OSATS as compared to 2D-laparoscopy, robotic surgery provided additional benefits. Furthermore, fewer additional side-effects of 3D-vision were found in the robotic group compared to the 3D-laparoscopy group.

A 2017 worldwide survey on opinions and use of MIPD found that $35 \%$ of the participants felt that robotic surgery was superior to (2D) laparoscopic surgery and $64 \%$ of the participants stated that the reason for superiority was, among other reasons, 3D-vision [29]. Since this study also included 3D-laparoscopy, the shorter operative time and better OSATS ratings provided by robotic surgery were due to other elements of the robot: the wristed articulating instruments with stability and scaling control, the 3rd and 4th arm (scope) of the robot, the surgeon's control of the camera, elimination of tremor, and ergonomic console.

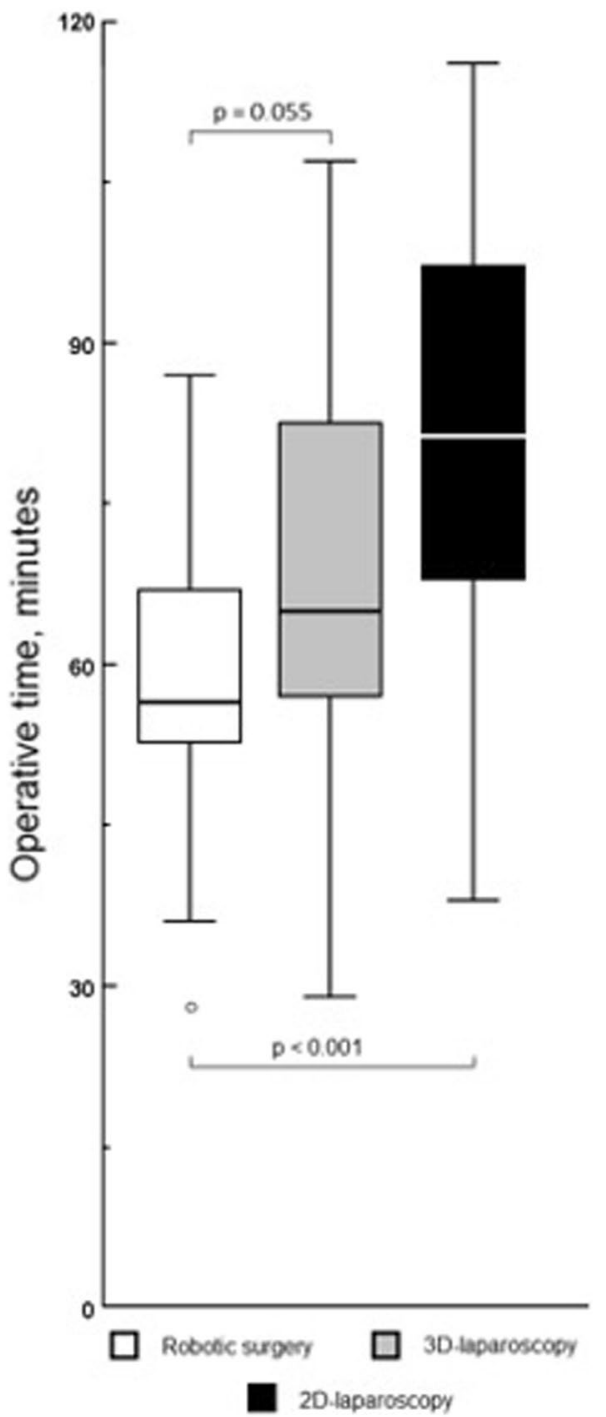

Fig. 3 Operative time with robotic surgery, 3D-, and 2D-laparoscopy to complete biotissue pancreatico- and hepatico-jejunostomy anastomoses. Legend: From left to right: first, 3D-robotic surgery $(n=20)$; second, 3D-laparoscopy $(n=35)$; third, 2D-laparoscopy $(n=35)$

Robotic pancreatoduodenectomy was compared to laparoscopy in several clinical studies $[15,30]$. In these, the effect of 3D-vision was largely ignored or overlooked. The majority of these studies found faster operative times in the robotic group, accompanied by similar postoperative complications [15].

By looking at expert and fellow performance using the same biotissue model, Tam et al. determined that the biotissue operative time can be generalized to clinical surgical performance [16]. Similarly, biotissue OSATS scores also translated to clinical surgical performance $[27,31]$ and were predictive for postoperative outcomes such as complications $[27,32,33]$. These studies used a PJ according to the modified Blumgart approach, since literature on the OSATS is 
Table 3 Complaints caused by 3D vision

\begin{tabular}{|c|c|c|c|c|c|}
\hline & None & Minor & Moderate & Serious & Severe \\
\hline \multicolumn{6}{|l|}{ Eye strain } \\
\hline Laparoscopic, $n(\%)$ & $29(74.4)$ & $8(20.5)$ & $0(0)$ & $0(0)$ & $2(5.1)$ \\
\hline Robotic, $n(\%)$ & $18(90.0)$ & $2(10.0)$ & $0(0)$ & $0(0)$ & $0(0)$ \\
\hline \multicolumn{6}{|l|}{ Headache } \\
\hline Laparoscopic, $n(\%)$ & $36(92.3)$ & $2(5.1)$ & $0(0)$ & $1(2.6)$ & $0(0)$ \\
\hline Robotic, $n(\%)$ & $18(90.0)$ & $1(5.0)$ & $0(0)$ & $1(5.0)$ & $0(0)$ \\
\hline \multicolumn{6}{|l|}{ Dizziness } \\
\hline Laparoscopic, $n(\%)$ & $33(84.6)$ & $4(10.3)$ & $2(5.1)$ & $0(0)$ & $0(0)$ \\
\hline \multirow[t]{2}{*}{ Robotic, $n(\%)$} & $17(75.0)$ & $2(10.0)$ & $0(0)$ & $1(5.0)$ & $0(0)$ \\
\hline & \multicolumn{4}{|c|}{ Yes } & No \\
\hline \multicolumn{6}{|l|}{ Disorientation } \\
\hline Laparoscopic, $n(\%)$ & & \multicolumn{2}{|c|}{$4(10.3)$} & & $35(89.7)$ \\
\hline Robotic, $n(\%)$ & & \multicolumn{2}{|c|}{$0(0)$} & & $20(100)$ \\
\hline \multicolumn{6}{|l|}{ Physical discomfort } \\
\hline Laparoscopic, $n(\%)$ & & \multicolumn{2}{|c|}{$1(2.6)$} & & $38(97.4)$ \\
\hline Robotic, $n(\%)$ & & \multicolumn{2}{|c|}{$1(5.0)$} & & $19(95.0)$ \\
\hline \multicolumn{6}{|l|}{ Poor visualization } \\
\hline Laparoscopic, $n(\%)$ & & \multicolumn{2}{|c|}{$0(0)$} & & $39(100)$ \\
\hline Robotic, $n(\%)$ & & \multicolumn{2}{|c|}{$0(0)$} & & $20(100)$ \\
\hline \multicolumn{6}{|l|}{ Preferred 3D } \\
\hline Laparoscopic, $n(\%)$ & & \multicolumn{2}{|c|}{$37(94.9)$} & & $2(5.1)$ \\
\hline Robotic, $n(\%)$ & & \multicolumn{2}{|c|}{$20(100)$} & & $0(0)$ \\
\hline
\end{tabular}

Completed survey, lap $n=39$, robot $n=20$

Adapted from Zwart et al. 2019 [13], and Zwart et al. 2020 [24]

Table 4 Sensitivity analysis excluding participants with $>$ 7 years experience

\begin{tabular}{|c|c|c|c|c|}
\hline & Total $(n=40)$ & $\begin{array}{l}\text { Robotic surgery } \\
(n=20)\end{array}$ & $\begin{array}{l}\text { Laparoscopic } \\
\text { surgery }(n=20)\end{array}$ & $p$ value \\
\hline Age, mean, SD & $36 \pm 7$ & $38 \pm 9$ & $40 \pm 8$ & $0.343^{\mathrm{a}}$ \\
\hline Male, n $(\%)$ & $31(77.5)$ & $16(80.0)$ & $15(75.0)$ & $0.70^{\mathrm{b}}$ \\
\hline \multicolumn{5}{|l|}{ Surgical experience } \\
\hline $\begin{array}{l}\text { Years of experience with approach, } \\
\text { median [IQR] }\end{array}$ & $2[1-5]$ & $1[0-2]$ & $5[3-6]$ & $<0.001^{\mathrm{c}}$ \\
\hline Expert $^{\mathrm{e}}$ & & $1[1-2]$ & 6 [6-NA] & $<0.001^{\mathrm{c}}$ \\
\hline Resident $^{\mathrm{r}}$ & & $0[0-1]$ & $4[3-6]$ & 0.013 \\
\hline $\begin{array}{l}\text { Annual volume of advanced MI } \\
\text { procedures*, median (IQR) }\end{array}$ & $15[1-40]$ & $20[1-40]$ & $15[3-48]$ & $0.752^{\mathrm{c}}$ \\
\hline MIPDs performed, median (IQR) & $0[0-1]$ & $0[0-20]$ & $0[0-0]$ & $0.023^{\mathrm{c}}$ \\
\hline Hand dominance, $\mathrm{n}(\%)$ & & & & $-{ }^{b}$ \\
\hline Right & $34(85.0)$ & $17(85.0)$ & $17(85.0)$ & \\
\hline Left & $4(10.0)$ & $2(10.0)$ & $2(10.0)$ & \\
\hline Ambidextrous & $2(5.0)$ & $1(5.0)$ & $1(5.0)$ & \\
\hline Vision correction, $\mathrm{n}(\%)$ & $17(42.5)$ & $9(45.0)$ & $8(40.0)$ & $0.10^{\mathrm{b}}$ \\
\hline Minimal degrees of stereopsis & $60[20-100]$ & $60[20-100]$ & $60[40-100]$ & $0.812^{\mathrm{c}}$ \\
\hline
\end{tabular}

Values are mean $\pm \mathrm{SD}$, median [quartile 1-quartile 3] or $n$ (percentage)

${ }^{\text {a S}}$ Student's ttest, ${ }^{\mathrm{b}}$ Chisquare test, ${ }^{\mathrm{c}}$ Mann-Whitney U Test, *Minimally invasive surgery beyond appendectomy and cholecystectomy, experience as primary surgeon, ${ }^{\mathrm{r}}$ experience assisting or under direct supervision of primary surgeon 
validated for that method only [31]. It is unclear whether these results could be extrapolated to other types of anastomoses. Literature on colorectal and bariatric surgery suggest that minimally invasive surgical experience in years and volume impacts both operative and clinical outcomes [27, 32]. The experience in the present study was a median of 4 years, with a median of 20 advanced minimally invasive procedures annually, while experience up to 10 years and increasing procedure volume is reported to improve outcomes [34-37]. It is clear that the present study is reporting in the learning curve phase for many surgeons, especially robotic surgeons, and should ideally be repeated at a later point, i.e., with further implementation [38, 39].

Robotic instrumentation provided a major contribution to surgical performance in this experimental setting. However, as reviewed by Anderson et al. elements of the robotic platform can be applied to laparoscopic surgery as well, this may be relevant in order to reduce the high cost associated with robotic surgery [40]. One study from the USA, however, reported similar costs for robotic MIPD and open pancreatoduodenectomy when taking also the costs of complications and follow-up into account [41].

The results of this study should be interpreted in light of several limitations. First, the randomized trials were performed in an experimental setting using a biotissue model and not in clinical practice. In clinical practice, clearly much more situational variation would have been observed. However, the previously mentioned studies [16, 42] clearly demonstrate the clinical value of operative time and OSATS rating using a highly standardized biotissue model. Furthermore, the biotissue anastomoses were similar to the UPMC biotissue training program for robot pancreatoduodenectomy $[16,17]$. The UPMC group demonstrated that the implementation of their biotissue training program resulted in continued improvements of operative performance and patient outcomes after integration of trainees and expansion of selection criteria [34]. Several other studies have also suggested that the outcomes from biotissue simulation in pancreatoduodenectomy can support clinical performance [17-20, 23, 43]. Second, a large difference in experience was seen between participants in the robotic surgery and laparoscopic surgery groups. Even with less experience, still better outcomes were seen in the robotic surgery group. The sensitivity analysis revealed that the primary outcomes remained consistent despite this heterogeneity. Future studies including participants with more experience should determine the 'optimal' outcomes and the exact impact of the learning curve effect. Third, the robotic group and laparoscopic group performed the biotissue anastomoses in the same time period. However, some of the participants of the robotic group completed virtual reality simulation exercises, and this could have had an influence on the outcomes. Additionally, eight participants participated in both the laparoscopic and robotic trials which could have introduced bias due to familiarity with the setup and handling of the biotissue. Therefore, we excluded these participants in a sub-analysis and the results for the primary and secondary outcome remained consistent. Fourth, this study is not a paired comparison assessing one surgeon's platform in relation to another but a pooled analysis, so there could be some selection bias involved but this is a better "real world" comparison of a platform. Fifth, several other differences between robotic and laparoscopic surgery could not be controlled for, for instance, better ergonomics for the surgeon in the robotic approach. We cannot exclude the possibility that better ergonomics was (partly) responsible for the better performance with the robotic approach.

Strengths of this study include the pooling of data from two randomized controlled crossover trials, thus controlling for known and unknown confounders.

In conclusion, the present study demonstrated that robotic surgery provides additional benefits over 3D- and 2D-laparoscopy when creating pancreatic and biliary anastomoses in a biotissue model. Future randomized studies should confirm these benefits in the clinical setting.

Acknowledgements We would like to acknowledge the theatre staff for allowing us robot time in all participating centers and all participating surgeons and residents for their input.

Collaborators: L.A. Stibbe, Department of Surgery, Amsterdam UMC, University of Amsterdam, Amsterdam, the Netherlands

Author Contribution All listed individuals accept direct responsibility for the Robotic surgery versus 3D/2D-laparoscopy manuscript. These individuals fully meet the criteria for authorship defined below: 1 . Authors made substantial contributions to Design. 2. Authors participated in drafting the article. 3. Authors have given final approval of the version of the Robotic surgery versus 3D/2D-laparoscopy manuscript to be published.

\section{Declarations}

Disclosures Maurice J.W. Zwart and Marc G. Besselink received funding from the Amsterdam UMC for studies on safe implementation of robot-assisted and laparoscopic pancreatic surgery; funding from the Dutch Digestive Foundation (MLDS; Grant Number I16-05) for studies on the before mentioned topics; and funding from Intuitive (Grant Reference: Evidence-based implementation of robot-assisted pancreatoduodenectomy using simulation training, LAELAPS-3) for the nationwide Dutch LAELAPS-3 training program for robotic pancreatoduodenectomy. Leia R. Jones, Ignacio Fuente, Alberto Balduzzi, Kosei Takagi, Stephanie Novak, Luna A. Stibbe, Thijs de Rooij, Jony van Hilst, Bengt van Rijssen, Susan van Dieren, Aude Vanlander, Peter B. van den Boezem, Freek Daams, J. Sven D. Mieog, Bert A. Bonsing, Camiel Rosman, Sebastiaan Festen, Misha D. Luyer, Daan J. Lips, Arthur J. Moser, Melissa E. Hogg, Olivier R. Busch, Mohammad Abu Hilal, and Martijn W.J. Stommel have no conflict of interest or financial ties to disclose.

Open Access This article is licensed under a Creative Commons Attribution 4.0 International License, which permits use, sharing, 
adaptation, distribution and reproduction in any medium or format, as long as you give appropriate credit to the original author(s) and the source, provide a link to the Creative Commons licence, and indicate if changes were made. The images or other third party material in this article are included in the article's Creative Commons licence, unless indicated otherwise in a credit line to the material. If material is not included in the article's Creative Commons licence and your intended use is not permitted by statutory regulation or exceeds the permitted use, you will need to obtain permission directly from the copyright holder. To view a copy of this licence, visit http://creativecommons. org/licenses/by/4.0/.

\section{References}

1. Yan J-F, Pan Y, Chen K, Zhu H-P, Chen Q-L (2019) Minimally invasive pancreatoduodenectomy is associated with lower morbidity compared to open pancreatoduodenectomy: an updated meta-analysis of randomized controlled trials and high-quality nonrandomized studies. Medicine (Baltimore) 98:e16730. https:// doi.org/10.1097/MD.0000000000016730

2. Poves I, Burdío F, Morató O, Iglesias M, Radosevic A, Ilzarbe L, Visa L, Grande L (2018) Comparison of perioperative outcomes between laparoscopic and open approach for pancreatoduodenectomy: the PADULAP randomized controlled trial. Ann Surg 268:731-739. https://doi.org/10.1097/SLA.0000000000002893

3. Palanivelu C, Senthilnathan P, Sabnis SC, Babu NS, Srivatsan Gurumurthy S, Anand Vijai N, Nalankilli VP, Praveen Raj P, Parthasarathy R, Rajapandian S (2017) Randomized clinical trial of laparoscopic versus open pancreatoduodenectomy for periampullary tumours. Br J Surg 104:1443-1450. https://doi.org/10.1002/ bjs. 10662

4. van Hilst J, De Rooij T, Bosscha K, Brinkman DJ, Van Dieren S, Dijkgraaf MG, Gerhards MF, De Hingh IH, Karsten TM, Lips DJ, Luyer MD, Busch OR, Festen S, Besselink MG, Marsman HA, Van Gulik TM, Wicherts DA, Eshuis WJ, Stibbe LA, Nieveen van Dijkum EJ, Van Hooft JE, Fockens P, Van Laarhoven HW, Wilmink JW, Van de Vijver MJ, Bijlsma MF, Verheij J, Nio CY, Van Lienden KP, Van Tienhoven G, Schoorlemmer A, Creemers GJ, Van Eijck CH, Groot Koerkamp B, Bruno MJ, Eskens F, Nuyttens JJ, Pek C, Van der Schelling GP, Seerden TC, Patijn GA, Nieuwenhuijs VB, De Groot JW, Bonsing BA, Vahrmeijer A, Swijnenburg RJ, Mieog JSD, Van der Harst E, Den Dulk M, Olde Damink S, Dejong CH, Van Dam R, De Vos JM, Liem MS, Van Laarhoven CJ, Van Goor H, Van den Boezem PB, Van der Kolk BM, Stommel MW, Hermans JJ, Van Geenen EJ, Radema SA, Brosens LA, Scheepers JJ, Roos D, Boerma D, Te Riele W, Van Santvoort HC, Bollen TL, Wit F, Molenaar IQ, Haj Moham$\operatorname{mad}$ N, Van Leeuwen MS, Roele A, De Jong KP, De Meijer VE, Klaase JM, Kazemier G, Zonderhuis B, Daams F, Meijerink MR, Latenstein A, Van Rijssen LB, Nota C, Van Halsema E, Van Veldhuisen E, Vogel J, Janssen K, Scholten L, Daamen L, Walma M, Strijker M, Prins M, Zwart M, Suker M, Rombouts S, Mungroop T, Vissers F, Korrel M (2019) Laparoscopic versus open pancreatoduodenectomy for pancreatic or periampullary tumours (LEOPARD-2): a multicentre, patient-blinded, randomised controlled phase 2/3 trial. Lancet Gastroenterol Hepatol 4:199-207. https:// doi.org/10.1016/S2468-1253(19)30004-4

5. Klompmaker S, Van Hilst J, Wellner UF, Busch OR, Coratti A, D'Hondt M, Dokmak S, Festen S, Kerem M, Khatkov I, Lips DJ, Lombardo C, Luyer M, Manzoni A, Molenaar IQ, Rosso E, Saint-Marc O, Vansteenkiste F, Wittel UA, Bonsing B, Groot Koerkamp B, Abu Hilal M, Fuks D, Poves I, Keck T, Boggi U, Besselink MG (2020) Outcomes after minimally-invasive versus open pancreatoduodenectomy: A pan-european propensity score matched study. Ann Surg 271:356-363. https://doi.org/10.1097/ SLA.0000000000002850

6. Zhao Z, Yin Z, Hang Z, Ji G, Feng Q, Zhao Q (2017) A systemic review and an updated meta-analysis: minimally invasive vs open pancreaticoduodenectomy. Sci Rep 7:2220. https://doi.org/10. 1038/s41598-017-02488-4

7. King JC, Hogg ME, Zeh HJ, Zureikat AH (2018) Robotic-Assisted Pancreaticoduodenectomy (Whipple). In: Patel AOD (ed) The SAGES Manual of Robotic Surgery. Springer International Publishing, Cham, pp 281-296

8. Cai J, Ramanathan R, Zenati MS, Al Abbas A, Hogg ME, Zeh HJ, Zureikat AH (2020) Robotic pancreaticoduodenectomy is associated with decreased clinically relevant pancreatic fistulas: a propensity-matched analysis. J Gastrointest Surg 24:1111-1118. https://doi.org/10.1007/s11605-019-04274-1

9. Waters JA, Canal DF, Wiebke EA, Dumas RP, Beane JD, AguilarSaavedra JR, Ball CG, House MG, Zyromski NJ, Nakeeb A, Pitt HA, Lillemoe KD, Schmidt CM (2010) Robotic distal pancreatectomy: cost effective? Surgery 148:814-823. https://doi.org/10. 1016/j.surg.2010.07.027

10. Kowalsky SJ, Zenati MS, Steve J, Esper SA, Lee KK, Hogg ME, Zeh HJ, Zureikat AH (2019) A combination of robotic approach and ERAS pathway optimizes outcomes and cost for pancreatoduodenectomy. Ann Surg 269:1138-1145. https://doi.org/10. 1097/SLA.0000000000002707

11. Akinbiyi T, Reiley CE, Saha S, Burschka D, Hasser CJ, Yuh DD, Okamura AM (2006) Dynamic augmented reality for sensory substitution in robot-assisted surgical systems. In: Annual international conference of the IEEE engineering in medicine and biology - proceedings. IEEE, pp 567-570

12. Amirabdollahian F, Livatino S, Vahedi B, Gudipati R, Sheen P, Gawrie-Mohan S, Vasdev N (2018) Prevalence of haptic feedback in robot-mediated surgery: a systematic review of literature. J Robot Surg 12:11-25. https://doi.org/10.1007/s11701-017-0763-4

13. Zwart MJW, Fuente I, Hilst J, de Rooij T, van Dieren S, van Rijssen LB, Schijven MP, Busch ORC, Luyer MD, Lips DJ, Festen S, Abu Hilal M, Besselink MG, Dutch Pancreatic Cancer Group (2019) Added value of 3D-vision during laparoscopic biotissue pancreatico- and hepaticojejunostomy (LAELAPS 3D2D): an international randomized cross-over trial. HPB (Oxford) 21:10871094. https://doi.org/10.1016/j.hpb.2019.04.012

14. Zhang H, Guo X, Xia J, Zhu F, Shen M, Wang X, Wang M, Qin R (2018) Comparison of totally 3-dimensional laparoscopic pancreaticoduodenectomy and open pancreaticoduodenectomy. Pancreas 47:592-600. https://doi.org/10.1097/MPA.0000000000001036

15. Kamarajah SK, Bundred J, Saint MO, Jiao LR, Manas D, Hilal MA, White SA (2019) Robotic versus conventional laparoscopic pancreaticoduodenectomy a systematic review and meta-analysis. Eur J Surg Oncol 46:6-14. https://doi.org/10.1016/j.ejso.2019.08. 007

16. Tam V, Zenati M, Novak S, Chen Y, Zureikat AH, Zeh HJ, Hogg ME (2017) Robotic pancreatoduodenectomy biotissue curriculum has validity and improves technical performance for surgical oncology fellows. J Surg Educ 74:1057-1065. https://doi.org/10. 1016/j.jsurg.2017.05.016

17. Hogg ME, Tam V, Zenati M, Novak S, Miller J, Zureikat AH, Zeh HJ (2017) Mastery-based virtual reality robotic simulation curriculum: the first step toward operative robotic proficiency. J Surg Educ 74:477-485. https://doi.org/10.1016/j.jsurg.2016.10. 015

18. Haney CM, Karadza E, Limen EF, de Santibanes M, Kinny-Köster B, Müller PC, Bintintan VV, Kulu Y, Hackert T, Müller-Stich B-P, Nickel F (2020) Training and learning curves in minimally invasive pancreatic surgery: from simulation to mastery. J Pancreatol 3:101-110. https://doi.org/10.1097/jp9.0000000000000050 
19. Nota CL, Zwart MJ, Fong Y, Hagendoorn J, Hogg ME, Koerkamp BG, Besselink MG, Molenaar IQ (2017) Developing a robotic pancreas program: the Dutch experience. J Vis Surg 3:106-106

20. Zwart MJW, Nota CLM, de Rooij T, van Hilst J, te Riele WW, van Santvoort HC, Hagendoorn J, Rinkes IHMB, van Dam JL, Latenstein AEJ, Takagi K, Tran TCK, Schreinemakers J, van der Schelling G, Wijsman JH, Festen S, Daams F, Luyer MD, de Hingh IHJT, Mieog JSD, Bonsing BA, Lips DJ, Hilal MA, Busch OR, Saint-Marc O, Zeh HJ, Zureikat AH, Hogg ME, Molenaar IQ, Besselink MG, Koerkamp BG (2021) Outcomes of a multicenter training program in robotic pancreatoduodenectomy (LAELAPS-3). Ann Surg Publish Ah: https://doi.org/10.1097/sla.00000 00000004783

21. World Medical Association (2013) World Medical Association Declaration of Helsinki. JAMA 310:2191. https://doi.org/10.1001/ jama.2013.281053

22. Schulz KF, Altman DG, Moher D, CONSORT Group (2010) CONSORT 2010 statement: updated guidelines for reporting parallel group randomised trials. BMJ 340:c332. https://doi.org/ 10.1136/bmj.c332

23. Zwart MJW, Foppen M, van Hilst J, de Rooij T, Busch ORC, Besselink MG (2019) How to teach and train laparoscopic pancreatoduodenectomy. Ann Pancreat Cancer 2:5-5

24. Zwart MJW, Jones LR, Balduzzi A, Takagi K, Vanlander A, van den Boezem PB, Daams F, Rosman C, Lips DJ, Moser AJ, Hogg ME, Busch ORC, Stommel MWJ, Besselink MG (2020) Added value of $3 \mathrm{D}$-vision during robotic pancreatoduodenectomy anastomoses in biotissue (LAEBOT 3D2D): a randomized controlled cross-over trial. Surg Endosc. https://doi.org/10.1007/ s00464-020-07732-z

25. Garnham L, Sloper J (2006) Effect of age on adult stereoacuity as measured by different types of stereotest. Br J Ophthalmol 90:91-95. https://doi.org/10.1136/bjo.2005.077719

26. Martin JA, Regehr G, Reznick R, Macrae H, Murnaghan J, Hutchison C, Brown M (1997) Objective structured assessment of technical skill (OSATS) for surgical residents. Br J Surg 84:273-278. https://doi.org/10.1002/bjs.1800840237

27. Birkmeyer JD, Finks JF, O'Reilly A, Oerline M, Carlin AM, Nunn AR, Dimick J, Banerjee M, Birkmeyer NJO (2013) Surgical skill and complication rates after bariatric surgery. N Engl J Med 369:1434-1442. https://doi.org/10.1056/nejmsa1300625

28. Sullivan GM, Artino AR (2013) Analyzing and interpreting data from likert-type scales. J Grad Med Educ 5:541-542. https://doi. org/10.4300/jgme-5-4-18

29. van Hilst J, de Rooij T, Abu Hilal M, Asbun HJ, Barkun J, Boggi U, Busch OR, Conlon KCP, Dijkgraaf MG, Han H-S, Hansen PD, Kendrick ML, Montagnini AL, Palanivelu C, Røsok BI, Shrikhande SV, Wakabayashi G, Zeh HJ, Vollmer CM, Kooby DA, Besselink MGH (2017) Worldwide survey on opinions and use of minimally invasive pancreatic resection. HPB (Oxford) 19:190-204. https://doi.org/10.1016/j.hpb.2017.01.011

30. Nickel F, Haney CM, Kowalewski KF, Probst P, Limen EF, Kalkum E, Diener MK, Strobel O, Müller-Stich BP, Hackert T (2020) Laparoscopic versus open pancreaticoduodenectomy: a systematic review and meta-analysis of randomized controlled trials. Ann Surg 271:54-66. https://doi.org/10.1097/SLA.00000 00000003309

31. Hogg ME, Zenati M, Novak S, Chen Y, Jun Y, Steve J, Kowalsky SJ, Bartlett DL, Zureikat AH, Zeh HJ (2016) Grading of surgeon technical performance predicts postoperative pancreatic fistula for pancreaticoduodenectomy independent of patient-related variables. Ann Surg 264:482-491. https://doi.org/10.1097/SLA.00000 00000001862

32. Stulberg JJ, Stulberg JJ, Huang R, Kreutzer L, Ban K, Champagne BJ, Steele SR, Johnson JK, Holl JL, Greenberg CC, Bilimoria KY (2020) Association between surgeon technical skills and patient outcomes. JAMA Surg 155:960-968. https://doi.org/10.1001/ jamasurg.2020.3007

33. Curtis NJ, Foster JD, Miskovic D, Brown CSB, Hewett PJ, Abbott S, Hanna GB, Stevenson ARL, Francis NK (2020) Association of surgical skill assessment with clinical outcomes in cancer surgery. JAMA Surg 155:590-598. https://doi.org/10.1001/jamasurg.2020. 1004

34. Zureikat AH, Beane JD, Zenati MS, Al Abbas AI, Boone BA, Moser AJ, Bartlett DL, Hogg ME, Zeh HJ (2019) 500 Minimally invasive robotic pancreatoduodenectomies. Ann Surg Publish Ah: https://doi.org/10.1097/sla.0000000000003550

35. Dokmak S, Ftériche FS, Aussilhou B, Lévy P, Ruszniewski P, Cros J, Vullierme MP, Khoy Ear L, Belghiti J, Sauvanet A (2017) The largest European single-center experience: 300 laparoscopic pancreatic resections. J Am Coll Surg 225:226-234.e2. https://doi. org/10.1016/j.jamcollsurg.2017.04.004

36. Kutlu OC, Lee JE, Katz MH, Tzeng CWD, Wolff RA, Varadhachary GR, Vauthey JN, Fleming JB, Conrad C (2018) Open pancreaticoduodenectomy case volume predicts outcome of laparoscopic approach: a population-based analysis. Ann Surg 267:552-560. https://doi.org/10.1097/SLA.0000000000002111

37. Adam MA, Thomas S, Youngwirth L, Pappas T, Roman SA, Sosa JA (2017) Defining a hospital volume threshold for minimally invasive pancreaticoduodenectomy in the United States. JAMA Surg 152:336-342. https://doi.org/10.1001/jamasurg.2016.4753

38. de Rooij T, van Hilst J, Boerma D, Bonsing BA, Daams F, van Dam RM, Dijkgraaf MG, van Eijck CH, Festen S, Gerhards MF, Koerkamp BG, van der Harst E, de Hingh IH, Kazemier G, Klaase J, de Kleine RH, van Laarhoven CJ, Lips DJ, Luyer MD, Molenaar IQ, Patijn GA, Roos D, Scheepers JJ, van der Schelling GP, Steenvoorde P, Vriens MR, Wijsman JH, Gouma DJ, Busch OR, Hilal MA, Besselink MG (2016) Impact of a nationwide training program in minimally invasive distal pancreatectomy (LAELAPS). Ann Surg 264:754-762. https://doi.org/10.1097/SLA.0000000000 001888

39. de Rooij T, van Hilst J, Topal B, Bosscha K, Brinkman DJ, Gerhards MF, de Hingh IH, Karsten TM, Lips DJ, Luyer MD, Marsman HA, van Rijssen LB, Steen MW, Busch OR, Festen S, Besselink MG (2019) Outcomes of a multicenter training program in laparoscopic pancreatoduodenectomy (LAELAPS-2). Ann Surg 269:344-350. https://doi.org/10.1097/SLA.0000000000002563

40. Anderson PL, Lathrop RA, Webster RJ (2016) Robot-like dexterity without computers and motors: a review of hand-held laparoscopic instruments with wrist-like tip articulation. Expert Rev Med Devices 13:661-672

41. Baker EH, Ross SW, Seshadri R, Swan RZ, Iannitti DA, Vrochides D, Martinie JB (2016) Robotic pancreaticoduodenectomy: comparison of complications and cost to the open approach. Int J Med Robot Comput Assist Surg 12:554-560. https://doi.org/10.1002/ rcs. 1688

42. Hogg ME, Zenati M, Novak S, Chen Y, Zureikat AH, Zeh IHJ (2016) 2016 Scientific session of the Society of American Gastrointestinal and Endoscopic Surgeons (SAGES), Boston, Massachusetts, USA, 16-19 March 2016. Surg Endosc 30:317-324. https://doi.org/10.1007/s00464-016-4772-6

43. Jones LR, Zwart MJW, Molenaar IQ, Koerkamp BG, Hogg ME, Hilal MA, Besselink MG (2020) Robotic pancreatoduodenectomy: patient selection, volume criteria, and training programs. Scand J Surg 109:29-33. https://doi.org/10.1177/1457496920 911815

Publisher's Note Springer Nature remains neutral with regard to jurisdictional claims in published maps and institutional affiliations. 


\section{Authors and Affiliations}

Maurice J. W. Zwart ${ }^{1} \cdot$ Leia R. Jones $^{1,2}(1) \cdot$ Ignacio Fuente $^{3} \cdot$ Alberto Balduzzi $^{1,4} \cdot$ Kosei Takagi $^{5,6} \cdot$ Stephanie Novak $^{7}$. Luna A. Stibbe ${ }^{1}$. Thijs de Rooij ${ }^{1}$. Jony van Hilst ${ }^{1}$. L. Bengt van Rijssen ${ }^{1}$. Susan van Dieren ${ }^{1}$. Aude Vanlander ${ }^{8}$. Peter B. van den Boezem ${ }^{9}$. Freek Daams ${ }^{10}$. J. Sven D. Mieog ${ }^{11}$. Bert A. Bonsing ${ }^{11}$. Camiel Rosman ${ }^{9}$. Sebastiaan Festen ${ }^{12}$. Misha D. Luyer ${ }^{13}$. Daan J. Lips ${ }^{14}$ - Arthur J. Moser ${ }^{15}$. Olivier R. Busch ${ }^{1}$. Mohammad Abu Hilal ${ }^{2}$. Melissa E. Hogg ${ }^{16} \cdot$ Martijn W. J. Stommel $^{9} \cdot$ Marc G. Besselink $^{1} \cdot$ for the Dutch Pancreatic Cancer Group

1 Department of Surgery, Amsterdam UMC, University of Amsterdam, Cancer Center Amsterdam, De Boelelaan 1117 (ZH-7F), 1081 HV Amsterdam, The Netherlands

2 Department of General Surgery, Instituto Ospedaliero Fondazione Poliambulanza, Brescia, Italy

3 Department of Surgery, Hospital Italiano de Buenos Aires, Buenos Aires, Argentina

4 General and Pancreatic Surgery Department, Pancreas Institute, University and Hospital Trust of Verona, Verona, Italy

5 Department of Surgery, Erasmus University Medical Center, Rotterdam, The Netherlands

6 Department of Gastroenterological Surgery, Transplant, and Surgical Oncology, Okayama University, Okayama, Japan

7 Department of Surgery, Hillman Cancer Center, University of Pittsburgh Medical Center, Pittsburgh, PA, USA

8 Department of Surgery, University Hospital Ghent, University of Ghent, Ghent, Belgium
9 Department of Surgery, Radboud University Medical Center, Nijmegen, The Netherlands

10 Department of Surgery, Amsterdam UMC, VU University, Cancer Center Amsterdam, Amsterdam, The Netherlands

11 Department of Surgery, Leiden University Medical Center, Leiden, The Netherlands

12 Department of Surgery, OLVG, Amsterdam, The Netherlands

13 Department of Surgery, Catharina Hospital, Eindhoven, The Netherlands

14 Department of Surgery, Medisch Spectrum Twente, Enschede, The Netherlands

15 Department of Surgery, Beth Israel Deaconess Medical Center, Harvard Medical School, Boston, MA, USA

16 Department of Surgery, Northshore University Health System, Chicago, IL, USA 